\title{
Rating the Action Programmes for Flood Prevention with AHP-ANP models: an evaluation of collective prevention effort
}

\begin{abstract}
664 Million EUR related to flood damages is compensated each year in average. To take in account collective prevention's efficiency to reduce damages on territories, this research project aims to experiment a national rating system of collective prevention actions through expert valuation. Action Programmes for Flood Prevention (PAPI) are the one key public policy instrument to manage flood risk in France. To score collective prevention through PAPI, we propose an original use of AHP-ANP models to weight the different categories of actions that PAPI can mobilize, with the contribution of representatives of all flood risk stakeholders.
\end{abstract}

Keywords: PAPI, collective prevention, vulnerability to flooding.

\section{Introduction}

664 Million EUR is provided as an annual average by French insurance undertakings to compensate flood-related damages to property. Damaging climatic events' cost is expected to double by 2040 (AFA, 2015). Thus, it questions vulnerability assessment, defined as damaging propensity. In addition, collective prevention actions implemented on territories have an impact on local vulnerability. This research project aims to experiment a national rating system of collective prevention actions' efficiency through expert valuation.

To investigate collective prevention, Action Programmes for Flood Prevention (PAPI) are the key public policy instrument in France. The constitution of a PAPI actions' database, homogenized through a codification process, provides 82 codes reflecting the diversity of actions. Rating such varied codes requires multi-criteria analyses. With the use of complete aggregation methods, and the opportunity to handle interdependencies, AHPANP models have been identified as a promising approach. We use them in an original way to weight the different codes of actions that finally allow scoring PAPI.

\section{Experimental design and complementarity of ANP and AHP models}

To reach the strategic objective to reduce damaging propensity, two main factors have been widely identified: exposure and sensitivity (Gallopin, 2006). Prevention actions will affect one or both factors, through reduction and/or non-aggravation. 
However, rating 82 codes regarding these global criteria is not relevant and calls for a more structured problem. In this perspective, varied works have identified several prevention levers (Ashley et al, 2010; Hegger et al., 2014). The advantage to consider prevention levers is to take in account their interdependencies, as they constitute all the facets of an integrated flood risk management (FRM) strategy. Thus, we use a top ANP model with relative weighting, feedback and self-loop for alternatives cluster as following:

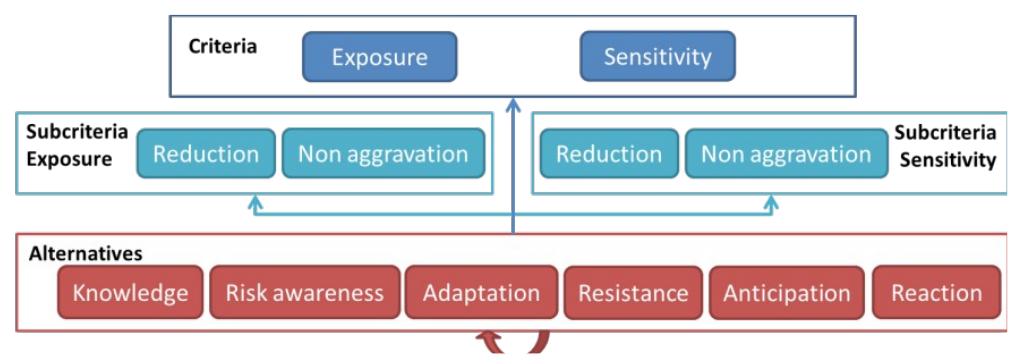

Figure 1 - ANP model to rate the six levers of collective prevention action

Codes of action may contribute to one or several prevention levers. AHP models were built for each prevention lever to score each 82 codes' contribution using ratings.

\section{Experts' panel design}

Regarding the diversity of actions implemented in PAPI, the constituted panel gathers: -both transversal experts and specific experts regarding each six main lever of actions -representatives of FRM stakeholders: the State and its deconcentrated services at more local scales, territorial authorities, civil society and prevention experts which covers insurance professionals, non-governmental associations, private/public experts.

We collected experts' judgments separately and handled inconsistency during the interview with the expert. Judgments will be aggregated using geometric mean and arithmetic mean for ratings. Results will be confronted with the panel to be validated.

\section{Limitations and perspectives}

AHP-ANP allow structuring the complexity of FRM which helps to obtain judgments from experts. However, experts sometimes had difficulties to answer one specific question and not to give a global judgment that goes beyond the considered criterion. One explanation is the focus on damages reduction, which is not the only FRM's objective.

The complexity of FRM and the high number of alternatives required to operate tradeoffs implying a simplification of models so that it was the least time consuming. Ratings within AHP models lead sometimes to low differences between codes. This will need some further investigation to lead to an operational tool.

Our model already showed its capacity to contribute to a national feedback on PAPI. It will also be used to build a tool for insurance professional purpose that will consider in parallel data on initial vulnerability. 
ISAHP Article: A Style Guide for Paper Proposals To Be Submitted to the International Symposium on the Analytic Hierarchy Process 2016, London, U.K.

\section{Key References}

AFA (2015), Risques climatiques: quels impacts sur l'assurance contre les aléas naturels à l'horizon 2040 ?, 29p.

Gallopín, G. C. (2006). Linkages between vulnerability, resilience, and adaptive capacity. Global environmental change, 16(3), pp 293-303.

Ashley, R., Blanksby, J., Maguire, T., \& Leahy, T. (2010). Frameworks for adapting to flood risk: experiences from the $\mathrm{EU}^{\text {e }} \mathrm{s}$ flood resilient city project, International Association for Hydro-Environment Engineering and Research (IAHR).

Hegger, D. L. T., Green, C., Driessen, P. P. J., Bakker, M. H., Dieperink, C., Crabbé, A., ... \& Fournier, M. (2013). Flood Risk Management in Europe: Similarities and Differences between the STAR-FLOOD consortium countries. 